\title{
UPAYA MENINGKATKAN KEMAMPUAN GURU DALAM MENYUSUN RPP DARING MELALUI ACTIVE KNOWLEDGE SHARING
}

\author{
Wasito \\ SD Negeri 2 Belikurip \\ kembarw@gmail.com
}

\begin{abstract}
Abstrak
Penelitian ini bertujuan untuk meningkatkan Kemampuan guru dalam menyusun RPP Daring melalui active knowledge sharing. Penelitian merupakan Penelitian Tindakan Sekolah (PTS) yang dilaksanakan dalam 2 (dua) siklus. Lokasi penelitian ini yaitu di SD Negeri 2 Belikurip dengan subjek penelitian semua guru SD Negeri 2 Belikurip Tahun Pelajaran 2020/2021 yang berjumlah 8 orang. Penilaian Kemampuan Guru dilakukan dengan teknik observasi dengan lembar observasi. Validasi data dilakukan dengan teknik triangulasi. Pengumpulan data dilakukan melalui observasi. Analisis data dilakukan dengan teknik analisis deskriptip komparatif. Berdasarkan data empiris hasil penelitian diperoleh fakta bahwa pada kondisi awal hanya terdapat 1 orang guru $(12,50 \%)$ yang masuk predikat Baik dengan nilai rata-rata Kemampuan 56,3. Sementara itu, pada siklus I hasilnya menjadi 5 orang $(62,5 \%)$ yang masuk predikat Baik dengan nilai rata-rata 75,0. Selanjutnya, pada siklus II terjadi peningkatan kembali menjadi 2 orang guru $(25,0 \%)$ yang masuk predikat Amat Baik, sebanyak 6 orang guru (75 \%) yang masuk predikat Baik dengan nilai rata-rata Kemampuan guru 87,5. Berdasarkan hasil tersebut maka dapat disimpulkan bahwa active knowledge sharing dapat meningkatkan Kemampuan guru menyusun RPP Daring di SD Negeri 2 Belikurip Tahun Pelajaran $2020 / 2021$.
\end{abstract}

Kata kunci: Kemampuan guru, RPP , active knowledge sharing, online

\begin{abstract}
This study aims to improve the ability of teachers in compiling online lesson plans through active knowledge sharing. This research is a School Action Research (PTS) which is conducted in 2 (two) cycles. The location of this research is $S D$ Negeri 2 Belikurip with the research subjects of all teachers of $S D$ Negeri 2 Belikurip in the academic year 2020/2021, totaling 8 people. Teacher Ability Assessment is done by observation techniques with observation sheets. The data validation was done by using triangulation technique. Data collection was carried out through observation. Data analysis was performed using comparative descriptive analysis techniques. Based on empirical data from the research results, it was found that in the initial conditions there was only 1 teacher (12.50\%) who was included in the predicate Good with an average value of ability of 56.3. Meanwhile, in the first cycle the results were 5 people (62.5\%) who entered the Good predicate with an average value of 75.0. Furthermore, in the second cycle there was an increase again to 2 teachers (25.0\%) who were included in the Very Good predicate, as many as 6 teachers (75\%) who were included in the predicate Good with an average score of 87.5. Based on these results, it can be concluded that active knowledge sharing can improve the ability of teachers to compile online lesson plans at SD Negeri 2 Belikurip for the 2020/2021 academic year.
\end{abstract}

Keywords: Teacher ability, lesson plans, active knowledge sharing, online

\section{PENDAHULUAN}

Pandemi Covid 19 memberikan perubahan yang mendasar terhadap pola pembelajaran yang terjadi saat ini. Hal tersebut berdampak sangat masif pada semua jenjang pendidikan (Sadikin \& Hamidah, 2020). Kegiatan pembelajaran yang sedianya dilaksanakan dengan bertatap muka secara langsung (luring) harus diganti dengan pembelajaran yang basis nya online (daring)(Pratama \& Mulyati, 2020). Dimasa pandemi ragam alternatif penawaran aplikasi pembelajaran online kian laku (Dewantara \& Nurgiansah, 2021). Perubahan metode pembelajaran dari luring ke daring 
memberikan dampak yang cukup signifikan terhadap guru (Asmuni, 2020). Dampak yang paling nyata yaitu perangkat pembelajaran yang harus dipersiapkan oleh guru. pembelajaran daring ini menimbulkan permasalahan yang kompleks (Nurgiansah \& Sukmawati, 2020).

Perangkat pembelajaran merupakan unsur yang penting dalam proses pembelajaran. Salah satu perangkat pembelajaran yaitu RPP. RPP merupakan Rencana Pelaksanaan Pembelajaran. RPP berisi tentang hal-hal yang akan dilakukan oleh guru dalam memberikan materi pelajaran kepada siswa. Perubahan dari daring ke luring berpengaruh terhadap perubahan RPP yang dibuat oleh guru (Putria et al., 2020). Pengembangan RPP Daring dianjurkan untuk di kembangkan atau di setiap awal semester atau pada awal tahun pelajaran. Hal ini ditujukkan agar RPP Daring (Rencana Pelaksanaan Pembelajaran) telah tersedia lebih dahulu dalam setiap awal pelaksanaan pembelajaran. Proses penyusunan (pembuatan) atau pengembangan RPP Daring dapat dilakukan secara individu atau dengan secara berkelompok di KKG. Pengembangan RPP Daring yang dilakukan oleh guru secara individu atau secara bersama-sama melalui kelompok kerja guru (KKG) di dalam suatu sekolah tertentu semestinya harus difasilitasi dan disupervisi kepala sekolah atau guru senior yang ditunjuk oleh kepala sekolah.

Namun fakta yang ditemukan adalah masih banyak guru yang tidak mampu menyusun perangkat pembelajaran daring. Rendahnya kemampuan guru dalam menyusun RPP Daring disebabkan berbagai faktor. Salah satu penyebabnya adalan ketika seorang guru mengikuti kegiatan Diklat, seorang guru dalam memperoleh informasi yang diterima lewat pendidikan dan pelatihan belum tuntas secara mendalam sehingga pemahaman materi masih mengambang. Kenyataan ini berdampak guru enggan membuat RPP Daring karena masih merasa kebingungan dan mengambil jalan pintas dengan memnta RPP Daring guru yang lain, mengunduh dari internet maupun membeli CD perangkat pembelajaran.

Mengetahui permasalahan rendahnya kemampuan guru dalam menyusun RPP Daring dengan lengkap berdasarkan silabus, penulis berencana untuk melaksanakan suatu penelitian tindakan dengan menerapkan active knowledge sharing. Strategi Active knowledge sharing (Berbagi Pengetahuan dan Diskusi) adalah sebuah teknik yang sesuai untuk menarik para peserta dengan segera kepada materi pelajaran dengan cara saling berbagi/ bertukar pengetahuan (Yulisma \& Mariana, 2018). Active knowledge sharing merupakan salah satu strategi yang dapat membawa peserta untuk siap belajar materi pelajaran dengan cepat serta dapat digunakan untuk melihat tingkat kemampuan siswa untuk membentuk kerja sama tim (Sari, 2016).

Strategi pembelajaran Active Knowledge Sharing merupakan suatu cara yang baik untuk mengenalkan peserta pada materi pelajaran yang akan diajarkan (Apriliyana \& Kusmanto, 2016). Peserta diperintahkan untuk menjawab pertanyaan-pertanyaan yang ada dalam lembar kerja yang berupa kontruksi dari konsep. Penggunaan lembar kerja untuk memudahkan peserta dalam mengerjakan tugas dan untuk meningkatkan keterlibatan peserta dalam pembelajaran. Dengan menggunakan lembar kerja peserta juga dapat membantu meningkatkan keterampilan berkomunikasi peserta dengan mengungkapkan dan menjelaskan ide-ide secara detail melalui tulisan. Pada tahap berbagi pengetahuan memungkinkan semua peserta mengungkapkan pendapat dan saling tukar informasi dengan teman sebayanya, 
sehingga mereka dapat terlibat aktif dan saling bekerja sama.

Berdasarkan uraian tersebut, maka Kepala Sekolah ingin meningkatkan kemampuan guru dalam penyusunan RPP Daring dalam suatu tindakan yang hasil yang diharapkan guru akan dapat menguasai dan menyusun RPP Daring dengan benar, sehingga tindakan Kepala Sekolah yang diwujudkan dalam penelitian dengan judul "Upaya Meningkatkan Kemampuan Guru dalam Menyusun RPP Daring melalui Active Knowledge Sharing di SD Negeri 2 Belikurip Tahun Pelajaran $2020 / 2021$

\section{METODE PENELITIAN}

Penelitian ini dilaksanakan di SD Negeri 2 Belikurip Kecamatan Baturetno Kabupaten Wonogiri. Subjek penelitian ini yaitu guru yang mengajar di SD Negeri 2 Belikurip termasuk guru kelas, guru agama, dan guru olahraga. Penentuan tempat penelitian mempertimbangkan beberapa hal diantaranya : (a) Dalam melaksanakan penelitian tidak meninggalkan tugas, (b) hasil penelitian memberikan dampak pada tempat penelitian. Objek penelitian ini yaitu kemampuan guru dalam menyusun RPP Daring dengan menerapkan Active knowledge sharing.

Teknik pengumpulan data dalam penelitian ini yaitu menggunakan observasi, wawancara, The interview is a data collection with a path of question and answer (Nurgiansah, 2020), catatan lapangan, dan dokumentasi. Analisis data yang digunakan dalam penelitian yaitu analisis deskriptif komparatif yaitu dengan membandingkan nilai tes antar siklus dan indikator kinerja. Analisis data dilakukan dengan metode deskriptif prosentase. Data hasil observasi dianalisis dengan analisis deskriptif kualitatif berdasarkan hasil pengamatan dan refleksi tiap siklus. Diharapkan dengan menggunakan Active knowledge sharing , terjadi peningkatan kemampuan guru dalam menyusun RPP Daring penerapan dengan Active knowledge sharing.

Indikator keberhasilan penelitian ini yaitu 1) Terdapat peningkatan kemampuan guru dalam menyusun RPP daring setelah diberi tindakan dengan Active knowledge sharing , 2) Meningkatnya kemampuan guru dalam menyusun RPP Daring setelah penerapan Active knowledge sharing sebanyak $88 \%$ guru atau 7 orang guru. Penelitian direncanakan menggunakan tindakan daur ulang seperti yang dikembangkan oleh Penelitian ini menggunakan model penelitian menurut John Elliot dalam Subyantoro (2012:11), Kegiatan Active knowledge sharing teknik kunjungan kelas ini terdiri dari 4 (empat) tahap yaitu: (1) persiapan (planning), (2) Pelaksanaan, (3) pengamatan, dan (4) refleksi, Penelitian ini, dilaksanakan dalam dua siklus, selanjutnya pelaksanaan tindakan digambarkan sebagai berikut :

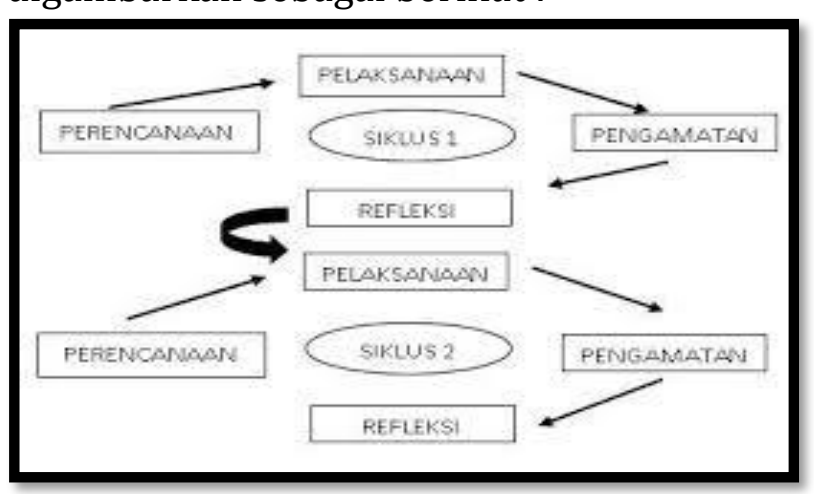

Gambar 1 Penelitian Tindakan Sekolah

\section{HASIL PENELITIAN DAN PEMBAHASAN Hasil Penelitian \\ Deskripsi Prasiklus}

Hasil pengamatan pada tahap prasiklus menunjukkan bahwa proses penyusunan RPP Daring yang terjadi di SDN 2 Belikurip keadaanya belum sesuai dengan kondisi yang ideal. Guru SDN 2 Belikurip yang mempunyai kewajiban untuk membuat RPP belum aktif ditunjukan dengan kurang mencari 
refrensi dalam menyusun RPP. Gambaran tersebut dapat diuraikan pada tabel berikut:

Tabel 1 Proses Penyusunan RPP Daring Daring Guru SDN 2 Belikurip Prasiklus

\begin{tabular}{|c|c|c|c|}
\hline No & Indikator & Ya & Tidak \\
\hline 1 & $\begin{array}{c}\text { Guru Aktif dalam } \\
\text { menyusun RPP. }\end{array}$ & 2 & 6 \\
\hline 3 & $\begin{array}{c}\text { Guru inisiatif } \\
\text { dalam proses } \\
\text { penyusunan RPP. }\end{array}$ & 3 & 5 \\
\hline $\begin{array}{c}\text { Guru Kolaboratif } \\
\text { dalam penyusunan } \\
\text { RPP. }\end{array}$ & 1 & 7 \\
\hline \multicolumn{2}{|c|}{ Prosentase } & \multicolumn{2}{|c|}{$25,00 \%$} \\
\hline Kategori & \multicolumn{2}{|c|}{ Kurang Baik } \\
\hline
\end{tabular}

Berdasarkan tabel tersebut, dapat dikemukakan bahwa guru yang aktif dalam penyusunan RPP daring sebanyak 2 guru, guru yang punya inisiatif dalam penyusunan RPP Daring sebanyak 3 dan guru yang berkolaborasi dalam penyusunan RPP daring sebanyak 1 . Secara keseluruhan proses penyusunan RPP Daring diprosentasekan sebesar $25,00 \%$ apabila dikategorikan dalam kategori kurang baik.

Selanjutnya, penyusunan RPP daring yang dilaksanakan oleh para guru SDN 2 Belikurip juga belum sesuai dengan harapan yang diinginkan, terlihat masih banyak guru yang belum memahaminya. Berikut merupakan tabulasi hasil penyusunan RPP daring pada tahap prasiklus:

Tabel 2 Hasil Penyusunan RPP Daring Prasiklus

\begin{tabular}{|c|c|c|c|c|}
\hline No & Kategori & $\begin{array}{c}\text { Rentang } \\
\text { Skor }\end{array}$ & $\begin{array}{c}\text { Jumlah } \\
\text { Guru }\end{array}$ & $(\%)$ \\
\hline 1. & $\begin{array}{c}\text { Baik } \\
\text { Sekali }\end{array}$ & $91-100$ & - & - \\
\hline 2. & Baik & $75-90$ & 1 & 12,5 \\
\hline 3. & Cukup & $55-74$ & 4 & 50,0 \\
\hline 4. & Kurang & $\mathrm{D}<55$ & 3 & 37,5 \\
\hline
\end{tabular}

\begin{tabular}{|c|c|c|}
\hline Jumlah & 8 & 100 \\
\hline
\end{tabular}

Tabel tersebut menunjukkan bahwa hasil penyusunan RPP daring pada tahap prasiklus 1 guru atau $12,5 \%$ mendapat kategori baik dengan skor 80. 4 guru mendapat skor 70 dan 60 atau 50,0\% dengan kriteria cukup. 3 guru mendapat skor 40 dengan nilai prosentase 37,5\% berkategori kurang. Kesimpulan yang dapat diambil mengacu pada hasil tersebut yaitu penyusunan RPP daring pada tempat penelitian masih termasuk kategori rendah. Oleh karena itu, perlu adanya pemberian tindakan pada siklus I.

\section{Siklus I}

Pada saat pelaksanaan siklus I, peneliti menerapkan Active knowledge sharing untuk meningkatkan proses penyusunan RPP. Pelaksanaan Active knowledge sharing meliputi kegiatan melaksanakan pertemuan awal dengan guru yang disupervisi. Pada pertemuan ini, guru-guru dijelaskan tentang penyusunan RPP yang benar. Selain itu, pada kegiatan ini terjadi dialog antara peneliti dan guru sehingga keaktifan guru nampak terlihat. Proses penyusunan RPP Daring yang dilaksanakan oleh guru-guru SDN 2 Belikurip di siklus I sebagian sudah sesuai dengan hasil yang diharapkan. Proses penyusunan yang kurang baik pada prasiklus meningkat menjadi baik berpengaruh terhadap hasil penyusunan RPP Daring yang telah dibuat oleh para guru. Berikut adalah tabulasinya:

Tabel 3. Hasil Penyusunan RPP Daring Siklus I

\begin{tabular}{|c|c|c|c|c|}
\hline No & Kategori & $\begin{array}{c}\text { Rentang } \\
\text { Skor }\end{array}$ & $\begin{array}{c}\text { Jumlah } \\
\text { Guru }\end{array}$ & $(\%)$ \\
\hline 1. & $\begin{array}{c}\text { Baik } \\
\text { Sekali }\end{array}$ & $91-100$ & - & - \\
\hline 2. & Baik & $75-90$ & 5 & 62,5 \\
\hline 3. & Cukup & $55-74$ & 3 & 37,5 \\
\hline
\end{tabular}




\begin{tabular}{|c|c|c|c|c|}
\hline 4. & Kurang & $\mathrm{D}<55$ & - & - \\
\hline \multicolumn{3}{|c|}{ Jumlah } & 8 & 100 \\
\hline
\end{tabular}

Berdasarkan tabel tersebut, dapat dijelaskan bahwa 5 guru (62,5\%) berada pada kategori baik, sedangkan 3 guru $(37,5 \%)$ masuk pada kategori Cukup. Mengacu pada indicator keberhasilan, maka siklus I dinyatakan belum mencapai target sehingga perlu dilanjutkan ke siklus II.

\section{Siklus II}

Proses penyusunan RPP Daring yang dilaksanakan oleh guru-guru SDN 2 Belikurip di siklus II sebagian sudah sesuai dengan hasil yang diharapkan, sebagian guru sudah memahami. Proses penyusunan yang kurang baik pada prasiklus meningkat menjadi baik berpengaruh terhadap hasil penyusunan RPP Daring yang telah dibuat oleh para guru. Sebanyak 8 guru yang membuat RPP dan hasil supervisi penyusunan RPP Daring sebagai berikut:

Tabel 5 Hasil Penyusunan RPP Daring Siklus I

\begin{tabular}{|c|c|c|c|c|}
\hline No & Kategori & $\begin{array}{c}\text { Rentang } \\
\text { Skor }\end{array}$ & $\begin{array}{l}\text { Jumlah } \\
\text { Guru }\end{array}$ & $(\%)$ \\
\hline 1. & Baik Sekali & $91-100$ & 2 & 25 \\
\hline 2. & Baik & $75-90$ & 6 & 75 \\
\hline 3. & Cukup & $55-74$ & & - \\
\hline 4. & Kurang & $\mathrm{D}<55$ & - & - \\
\hline \multicolumn{3}{|c|}{ Jumlah } & 8 & 100 \\
\hline
\end{tabular}

Berdasarkan tabel tersebut dapat dijelaskan bahwa 25\% (2 guru) masuk kategori sangat baik, sedangkan sisanya $75 \%$ (6 guru) masuk kategori baik. Mengacu pada indicator keberhasilan, maka siklus II dinyatakan sudah mencapai target sehingga tidak perlu dilanjutkan ke siklus berikutnya.

\section{Pembahasan}

Perencanaan proses pembelajaran meliputi silabus dan RPP. Silabus merupakan sebagian sub-sistem pembelajaran yang terdiri dari atau yang satu sama yang lain saling berhubungan dalam rangka mencapai tujuan. Hal penting yang berkaitan dengan pembelajaran adalah penjabaran tujuan yang disusun berdasarkan indikator yang ditetapkan. Perencanaan program pembelajaran merupakan suatu penetapan yang memuat komponen-komponen pembelajaran secara sistematis. Analisis sistematis merupakan proses perkembangan pendidikan yang akan mencapai tujuan pendidikan agar lebih efektif dan efisien disusun secara logis, rasional, sesuai dengan kebutuhan siswa, sekolah, dan daerah (masyarakat). Perencanaan program pembelajaran adalah hasil pemikiran, berupa keputusan yang akan dilaksanakan.

Perubahan proses pembelajaran dari luring ke daring berdampak pada berubahnya RPP yang digunakan oleh guru. RPP daring perlu dipersiapkan untuk melaksanakan pembelajaran secara daring di sekolah. Daring merupakan singkatan dari dalam jaringan yang mana suatu pengganti dari kata online. Daring membutuhkan koneksi internet agar dapat terhubung antara client dengan server atau siswa dengan guru. Sementara, luring adalah singkatan dari luar jaringan yang mana pengganti dari kata offline. Luring tidak membutuhkan koneksi internet dalam artian tidak memakai jaringan untuk menghubungkan guru dengan siswa.

RPP Daring adalah Rencana Pelaksanaan Pembelajaran yang dilakukan secara Online, guru tetap harus membuat RPP Daring sebagai proses belajar mengajar yang dilakukan jarak jauh atau secara Online dengan siswa dirumah. Kemampuan guru dalam menyusun RPP daring sangat penting untuk ditingkatkan agar kualitas pembelajaran dapat terjaga 
dengan baik. Pada penelitian ini, peneliti memilih menggunakan Active Knowledge Sharing untuk meningkatkan kemampuan menyusun RPP daring. Hasilnya yaitu, Active Knowledge Sharing terbukti mampu meningkatkan kemampuan guru dalam menyusun RPP daring bagi para guru.

Telah banyak dilakukan penelitian dengan penerapan metode Active Knowledge Sharing. (Yulisma \& Mariana, 2018) mengemukakan bahwa model Model Active Knowledge Sharing memiliki pengaruh terhadap aktivitas belajar siswa. Artinya aktivitas belajar menjadi meningkat setelah diberi tindakan dengan metode tersebut. Sementara itu, (Ariasa et al., 2014) juga mengemukakan bahwa pembelajaran dengan model Model Active Knowledge Sharing berdampak pada hasil belajar peserta didik. Oleh karena itu, dapat dikemukakan kembali bahwa Model Active Knowledge Sharing mampu meningkatkan kemampuan guru dalam menyusun RPP daring pada guru.

\section{KESIMPULAN}

Kesimpulan dari penelitian ini yaitu model Active Knowledge Sharing dapat meningkatkan Kemampuan guru menyusun RPP Daring di SD Negeri 2 Belikurip Tahun Pelajaran 2020/2021.

\section{DAFTAR PUSTAKA}

Apriliyana, R., \& Kusmanto, B. (2016). Penerapan Strategi Active Knowledge Sharing Untuk Meningkatkan Minat Dan Prestasi Belajar Matematika Siswa Kelas Xa Sma Piri 1 Yogyakarta. Jurnal Pendidikan Matematika, 4(1), 117-124.

Ariasa, I. K., Wiyasa, i km ngr, \& Kristiantari, mg rini. (2014). Pengaruh Model Pembelajaran Active Knowledge Sharing Terhadap Hasil Belajar Matematika Siswa Kelas V Sd Gugus Peliatan Ubud. Jurnal Mimbar PGSD Universitas Pendidikan Ganesha Jurusan PGSD, 2(1).

Asmuni, A. (2020). Problematika Pembelajaran Daring di Masa Pandemi Covid-19 dan Solusi Pemecahannya. Jurnal Paedagogy, 7(4), 281. https://doi.org/10.33394/jp.v7i4.2941

Dewantara, J. A., \& Nurgiansah, T. H. (2021). Efektivitas Pembelajaran Daring di Masa Covid19 Bagi Mahasiswa Universitas PGRI Yogyakarta. Jurnal Basicedu: Research \& Learning in Elementary Education, 5(1), 367-375.

Nurgiansah, T. H. (2020). Build An Attitude of Nationalism Students At SDN 7 Kadipaten With The Method of Discusion In The Subject PPKn. Jurnal Serunai Pendidikan Pancasila Dan Kewarganegaraan STKIP Budi Daya Binjai, 9(1), 1-11.

Nurgiansah, T. H., \& Sukmawati. (2020). Tantangan Guru Pendidikan Kewarganegaraan Di Masa Adaptasi Kebiasaan Baru. Jurpis: Jurnal Pendidikan Ilmu Sosial, 17(2), 139-149.

Pratama, R. E., \& Mulyati, S. (2020). Pembelajaran Daring dan Luring pada Masa Pandemi Covid-19. Gagasan Pendidikan Indonesia, $1(2), \quad 49-59$. https://doi.org/10.30870/gpi.v1i2.9405

Putria, H., Maula, L. H., \& Uswatun, D. A. (2020). Analisis Proses pembelajaran Dalam Jaringan (DARING) Masa Pandemi COVID-19 pada Guru Sekolah Dasar. Jurnal Basicedu, 4(4), 861872. https://doi.org/10.31004/basicedu.v4i4.460

Sadikin, A., \& Hamidah, A. (2020). Pembelajaran Daring di Tengah Wabah Covid-19. Biodik, 6(2), 109-119. https://doi.org/10.22437/bio.v6i2.9759

Sari, E. F. P. (2016). Penerapan Model Active Knowledge Sharing Dalam Pembelajaran Matematika Siswa Kelas VII di SMPN 18 Palembang. Jurnal Mosharafa, 5(3), 335-342.

Yulisma, L., \& Mariana, D. (2018). Pengaruh Penggunaan Model Active Knowledge Sharing Terhadap Aktivitas Belajar Siswa di SMAN 2 Ciamis. Jurnal Wahana Pendidikan, 5(2), 1-4. 